\title{
III FESTIVAL TEATRAL DE MOSCOU - 1935: A ESCRITA DE JORACY CAMARGO
}

\author{
Vera Collaço ${ }^{1}$
}

\section{Resumo}

Neste artigo analiso a leitura realizada por Joracy Camargo sobre o teatro que pode acompanhar na União Soviética, quando foi à Moscou, como integrante da delegação francesa, para participar do III Festival Teatral de Moscou realizado em outubro de 1935. Apresento as aproximações que Joracy estabeleceu entre o teatro brasileiro e o teatro soviético, e, por fim, o objeto central desta escrita, que é o diálogo travado por Joracy diante do que lhe era apresentado em Moscou.

Palavras-chave: Teatro Russo, Teatro Brasileiro, Percepção Histórica.

\begin{abstract}
In this paper I analyze the interpretation done by Joracy Camargo of the theater he had contact with in the Soviet Union when he went to Moscou as a member of the French delegation, to participate in the III Moscow Theatrical Festival, which took place in October of 1935. I expose the connections which Joracy draw between Brazilian theater and the Soviet theater, and, at the end I comment on the main issue of his writting, the dialogue established by Joracy on what it was presented to him in Moscou.
\end{abstract}

Keywords: Russian Theater, Brazilian Theater, historical perception.

Analisar o olhar do outro sobre determinado objeto estabelece também o nosso próprio olhar. Esta perspectiva define nossos recortes e escolhas espaço-temporais, e evidentemente, os nossos objetos preferenciais e que se tornam focos de estudos e obsessões. Quem era jovem no Brasil das décadas de 1960-1970, e possuía uma perspectiva histórica engajada nas questões sócio-políticas, tinha certamente um olhar que se dirigia à União Soviética - URSS - e a percebia como o foco de onde emanariam as transformações que se julgavam vitais para construir um novo paradigma social. Era um olhar encantado, utópico e que não conseguia ir além das aparências que lhe expunham os dois lados que dominavam o debate e as fontes geradoras das informações.

Foi este olhar que captei ao deparar-me com o relato de Joracy Camargo sobre sua estadia na União Soviética, em 1935, e imediatamente me

${ }^{1}$ Professora adjunta do Centro de Artes - UDESC, com atividades na graduação, mestrado e doutorado em teatro. Doutora em História Cultural. Desde 2005 vem pesquisando sobre o Teatro de Revista em Santa Catarina e no Brasil. 
interessou buscar o olhar e o recorte, ou seja, a leitura que ele realizou sobre o que lhe foi permitido perceber de sua estadia na URSS para acompanhar o III Festival Teatral de Moscou.

Neste sentido, este artigo resulta de dois olhares sobre o mesmo objeto - a URSS - e acrescido de uma paixão comum - o Teatro. Mas, é uma leitura realizada em dois tempos e conseqüentemente em duas leituras com compreensões e fundamentos históricos diferenciados. No artigo aqui proposto analiso, portanto, a leitura que Joracy Camargo, elaborou a partir de sua estadia na URSS. Mas, contraponho os dois tempos históricos ao olhar para a URSS, o de Joracy e o do meu tempo presente. Ressalto os apoios teóricos para sua escrita. Debato as aproximações que Joracy estabeleceu entre o teatro brasileiro e o teatro soviético, e, por fim, o objeto central desta escrita, que é o diálogo travado por Joracy diante do que lhe era apresentado em Moscou. A obra de Joracy permite adentrar em diferentes matizes de leituras sobre a percepção de um receptor muito especial. Neste artigo ficarei mais restrita à forma e a estrutura desta obra, sem deixar, contudo, de apontar para os referenciais mais macros a que nos remete este ensaio.

Em outubro de 1935 Joracy Schafflor Camargo (1898-1973), ou simplesmente Joracy Camargo, foi à União das Repúblicas Socialistas Soviéticas - URSS - para acompanhar o "Terceiro Festival Teatral de Moscou”. Este festival foi realizado em outubro de 1935 em homenagem ao 180 aniversário da Revolução Russa. No retorno de sua viagem, Joracy redigiu um ensaio, denominado de $O$ Teatro Soviético, com o objetivo relatar o que vivenciou e o que teve possibilidade de tomar conhecimento no período em que esteve na União Soviética.

O meu contato com esta obra se deu recentemente e fiquei muito feliz ao conhecer este trabalho, pois este ensaio significa uma excelente oportunidade de perceber como um dramaturgo brasileiro, de viés de esquerda, "leu” o que se passava na União Soviética em 1935; momento crucial, quando as vanguardas russas começavam a serem silenciadas pelo regime de Joseph Stalin (1878-1953). Portanto, estamos diante de um raro relato sobre o teatro revolucionário russo realizado por alguém de teatro que não estava diretamente envolvido nestes acontecimentos, mas que os olhava com muita curiosidade e simpatia. Diria mesmo que os olhava com um olhar quase religioso, com a compreensão de que está participando de um importante momento da história da humanidade.

A escrita deste ensaio resultou de seu desejo de "escrever a história de um povo, e principalmente a história de um povo que realiza uma experiência cujos primeiros resultados começam a aparecer”. (CAMARGO, 1945, p.12). E essa seria sua contribuição para a história do teatro, expor como um país 
"atrasado" desenvolveu um dos mais ricos modelos artísticos para o teatro. O ensaio está dividido em um prólogo e 18 capítulos, com um total de 279 páginas. No primeiro capitulo, ele faz uma retrospectiva da história russa, tendo por titulo "A tragédia do povo russo". E aponta para os governos de Pedro, o Grande e Catarina II como "os criadores da autocracia, a aristocracia e a escravatura, e por isso mesmo os primeiros responsáveis pela revolução de 1917”. (CAMARGO, 1945, p.12). A partir deste primeiro capítulo, o ensaio centra-se no teatro russo, embora não siga uma ordem cronológica, procura estabelecer o que ocorreu na Rússia pré-revolucionária até a URSS de 1935. É perceptível, muitas vezes, a dificuldade em discutir assuntos que estavam encobertos pelo regime comunista de Stalin, como por exemplo, o Realismo Socialista imposto aos artistas russos a partir de 1934, e a, conseqüente, negação de toda arte de vanguarda e experimental. Ou, ainda entender a importância de Maiakovski para o movimento revolucionário russo. Sobre este dramaturgo e poeta, comenta Joracy:

Vladimir Vladimirovitch Mayakovski (1894-1930) - foi o iniciador do futurismo no teatro, mas apenas conseguiu escandalizar o publico, apresentando-se no palco para recitar seus poemas, metido num a blusa amarela de mulher, com riscos verdes na cara. Maiakovski só conseguiu algum sucesso com a peça "Mistério Bufo" (1945, p. 51).

É possível detectar, na fala acima, a negação de um dos primeiros poetas da vanguarda russa e um militante partidário desde 1906. Ele foi um dos primeiros artistas, junto com Meierhold, a atender o chamado de Lunarcharski (1875-1933), em 1918, para discutir a nossa arte revolucionária. Maiakovski foi o poeta que mais completamente expressou, nas décadas em torno da Revolução de Outubro, os novos e contraditórios conteúdos do tempo e as novas formas que estes demandavam. Atuou de forma intensa no período do Agit-Prop, colocou sua arte a serviço da Revolução. Mas, também foi Maiakovski que com O Percevejo, encenada em 1929, e Os Banhos, encenada em 1930, ambas direções de Meierhold, afrontou o sistema, ao apontar criticas a burocracia estatal que estava dominado a União Soviética. Assim, após seus suicídio, em 1930, começou o desmonte de sua imagem, e o apagamento de sua contribuição a arte soviética. Tanto que, em 1935, quando Joracy Camargo tem contato com o que sobrou na URSS do artista, este encontra e relata apenas seus aspectos folclóricos e negativos.

\section{$\mathrm{O}$ convite e a viagem à Moscou}

Joracy Camargo integrou a delegação francesa de "pessoas envolvidas com o teatro" para acompanhar durante dez (10) dias o Terceiro Festival de Teatro, realizado em Moscou, em outubro de 1935. Com as palavras de Joracy: 
Fui à Rússia atraído pelo Festival Teatral de Moscou. Quando surgiu, em Paris, o programa anunciando o Terceiro Festival, e prometendo aos turistas dez dias maravilhosos, com a apresentação das maiores realizações de todos os gêneros de teatro levadas a efeito durante o ano de 1935, não resisti à tentação e logo me incorporei à caravana de homens de teatro da França que partiria por aqueles dias para a capital artística do mundo. (1945, p.54)

Pode-se perceber por sua fala final a grande empolgação que o envolvia. Tanto que na época, década de 1930, Paris era considerada a "capital artística do mundo”, mas para Joracy o olhar estava no outro lado, Moscou era o centro de seus interesses, ideológicos e artísticos.

Para dar visibilidade no ocidente, de suas conquistas revolucionárias, o governo de Stalin fez uma grande festividade para comemorar o 180 aniversário da Revolução de 1917. Foram convidados, e se fizeram presentes, para o Terceiro Festival de Teatro de Moscou, em outubro de 1935, delegações de 35 países. O festival foi elaborado para ocorrer durante 10 dias, numa clara referencia aos “10 dias que mudaram o mundo". O festival foi, portanto, um momento, claramente programado, para divulgar no ocidente a arte russa e as conquistas deste povo após a Revolução de 1917. Ao se ler os depoimentos de Joracy, após sua estadia na Rússia, pode-se afirmar que eles atingiram seus objetivos, deixando as diferentes delegações entusiasmadas com o que viam ocorrer na União Soviética. Transcrevo algumas frases de Joracy que atestam seu deslumbramento, e que ele faz questão de afirmar que era uma sensação coletiva, era o que estava perpassando pela delegação francesa. Gaston Baty "disse que o Teatro Frances lucraria muito, encontrando-se constantemente com o teatro soviético”. (CAMARGO, 1945, p.56). Charles Vidrac: "Bem sei que entre os que se apaixonaram pela arte dramática seria banal dizer que a expressão cênica na Rússia Soviética é a primeira do mundo, mas eu não resisto ao prazer de repetir essa banalidade”. (CAMARGO, 1945, p.56) e termina afirmando:

Estas opiniões, como todas as outras, e a minha, referiam-se aos resultados maravilhosos a que chegaram os artistas soviéticos em todas as artes, graças às facilidades de expansão das suas faculdades, e sobretudo aos elementos de que podiam dispor, em plena liberdade de ação. (CAMARGO, 1945, p.56)

Fica evidente, na leitura deste relato, que não foi apresentada as diferentes delegações a censura - o comitê Gkaurepertkov - em ação desde 1923. E a partir daí vários artistas, entre estes Meierhold, vão ter seus projetos barrados pelo referido comitê. 
Da delegação francesa, que fez parte Joracy Camargo, estavam entre os mais conhecidos atualmente: Gaston Baty - diretor do Teatro Montparnasse, Charles Dullin, Léon Moussinac, e muitos outros. Quando da chegada ao hotel, cada representante recebia a programação dos espetáculos para os dez dias de atividades. ${ }^{2}$ Foram levados à cena 14 espetáculos, entre adultos e infantis. $\mathrm{O}$ que chama a atenção é a ausência de espetáculo de Meierhold e de Stanislavski nesta programação. Dos grandes inovadores russos do século XX apenas Tairov se fez presente com o espetáculo: As Noites Egipcianas, que reunia textos de Shakespeare, Shaw e Puchkine. Mas, Joracy acabou assistindo, fora da programação do festival, ao espetáculo A Dama das Camélias, dirigido por Meierhold. Este espetáculo estreou em 19 de março de 1934, “o personagem de Margarida Gautier foi interpretado por Zinaida Raich, [esposa de Meierhold], foi sua última grande criação”. (HORMIGON, 1992, p.565).

\section{Como deixar de ponderar sobre a prática teatral no Brasil}

Durante sua estadia na União Soviética, e no envolvimento total com uma prática teatral que o abismava e o deixava exultante, Joracy Camargo não pode ausentar-se de traçar alguns breves, diria mesmo brevíssimos, pontos de contato ou de afastamento entre o teatro russo e a prática teatral brasileira.

Ao abordar as transformações realizadas por Meierhold na questão do "respeito" a obra do dramaturgo, observa Joracy:

Os próprios autores, “donos” exclusivos de suas produções, tiveram de sujeitar-se às mutilações e transformações do preparador do espetáculo, em harmonia geral com o seu sistema. Só assim Meierhold pode impor a bio-mecânica, e só assim a bio-mecânica seria possível, pois exige a subordinação de todos os elementos à forma de apresentação. (CAMARGO, 1945, p. 76)

Para Joracy, Meierhold “declarou guerra aos preconceitos dos autores, que, como os nossos [brasileiros], só permitem o corte de uma fala ou a colaboração do artista diante do fracasso da peça, para salvar a situação”. (CAMARGO, 1945, p.76). Era o princípio de um embate que se estenderia por toda a primeira metade do século XX, e que partia da pergunta base: quem é o autor da obra? O dramaturgo ou o encenador? Como o século XX pode ser considerado, especialmente no período citado, como o século dos encenadores, o que temos é que este embate foi se diluindo e pendendo para o artista encenador.

Também do trabalho de Meierhold vem outra comparação com o teatro que estava sendo realizado na Rússia e o teatro brasileiro. Ao abordar o cenário construtivista e a biomecânica, se referindo ao espetáculo dirigido por Meierhold, O Homem e as Massas, de Ernest Toller, Joracy questiona o leitor se
${ }^{2}$ Programação do
Terceiro Festival de Teatro de Moscou, tal como a expõe Joracy Camargo (1945, p.5758), estavam previstas a apresentação de 14 espetáculos: Grande Teatro: - 'Sadko', de Rimskikorsakov; Teatro dos Jovens Espectadores: - (matinée) 'Till Eulenspiegel', de Coster; Teatro Judeu: - (soirée) "O Rei Lear", de Shkespeare; Teatro Nemirovitch-Dantchenko: - "Katharina Ismailova", ópeta de Choistakovitch; Teatro da Criança: - "A Lenda do Pescador e do peixe", de Polivinkine, em matinée, e na "soirée" "O Cura Espanhol", de Fletcher; Teatro Cigano: - (matinée) "Carmen", de Bizet; Teatro dos Artistas Profissionais de Moscou: - "A Cidade dos Ventos", de Kirchon; Grande Teatro: - "Os Três Obesos", bailado de Oranskov; Teatro Realista: - "Os aristocratas", de Pogodine; Pequeno Teatro Acadêmico: "Os Combatentes", de Romachov; Teatro de Marionettes, ou Teatro do Livro Infantil, em "matinée"; Primeiro Teatro Acadêmico (Teatro Gorki): - "O Furacão" (p. 55), de Ostrovski; Teatro Tairov: - "As noites egipcianas", de Shakespeare-ShawPuchkine, Teatro Vakhtangov: - "O Ponto Distante" (Dalagoye), de A. Afinoguenov. 


\section{Urdimento}

(cont.) Além desse programam durante o curso da década de arte, várias projeções dos melhores filmes nos foram oferecidas gratuitamente, e dentre eles os seguintes: "Tchapáev", dos irmãos Vassilev; "As Jornadas Culminantes", de Zarkin e Heifetz; Ö Novo Gulliver", de P. Houchko; Ös Camponeses", de Ermler; "Os aviadores", de Raisman e "Pope", de Bek-Nazarov". ele seria capaz de aceitar este teatro. E responde: "também sei que não aceitou a inovação, por achar, naturalmente, que um 'cenário' de andaimes e escadas não dará a ninguém a impressão exata da representação de uma história, de um conflito ou de uma idéia”. (CAMARGO, 1945, p.80-81). E, instigando ainda mais seu leitor, ele sugere que este leitor deve preferir um cenário mais realista, mesmo que com elementos teatrais.

É que nós da chamada classe média estamos habituado a esse teatrinho inocente, que eu mesmo faço, por necessidade. Mas o povo, a massa popular, aceitaria e compreenderia a inovação, porque não pode habituar-se com o teatrinho burgues, feito para inteligências preguiçosas e tão inimigas do verdadeiro teatro […]. (CAMARGO, 1945, p. 81).

Nesta colocação temos um Joracy impregnado do pensamento marxista, que idealiza o que chama de "povo", e abomina o que denomina de pequena burguesia. A pequena burguesia é “incapaz” de entender a importância histórica das transformações, sejam elas sociais ou estéticas, e "as massas", na sua "rude ignorância", têm uma clara percepção do percurso histórico. Diferenciações bastante reprisadas no pensamento marxista deste período.

$\mathrm{O}$ ultimo paralelo traçado por Joracy Camargo se refere às leis de proteção aos artistas. E comenta que a situação dos artistas russos antes da Revolução era de extrema penúria.

Os salários eram muito baixos, e dependiam exclusivamente da vontade arbitrária dos empresários. Não havia uma lei que lhes desse personalidade jurídica, ou regulasse as relações entre os artistas e seus exploradores. Em suma, estavam na mesma situação em que a "Lei Getulio Vargas" [de 1928] encontrou os nossos artistas. (CAMARGO, 1945, p. 102).

Mas, observa Joracy, se para os artistas russos a situação alterou para melhor após a Revolução, os nossos artistas estagnaram, pois “os auxiliares do presidente da República” não deram continuidade a sua obra. Portanto, o problema, no Brasil, foi de gestão e não de amparo presidencial. Era preciso muito jogo de cintura para viver este momento do Brasil, e do embate entre o bloco comunista e o bloco capitalista, do qual o Brasil fazia parte.

Estas foram a poucas linhas que o autor dedicou a comparar os dois processos de organização e administração teatral. Mas, ele vai além de simples comparação e propõe, nas paginas 190 e 191, que o Brasil adapte para a nossa realidade, o trabalho desenvolvido por Natalia Satz com o Teatro da Criança. 
E ele fez essa proposição numa conferencia que ministrou, a pedido da Comissão Nacional de Teatro, em 1936, e que foi publicado em 1937 pelo Ministério da Educação e Saúde, de Gustavo Capanema. Evidentemente que suas propostas ficaram apenas no plano do seu escrito.

\section{Os espetáculos dos inovadores russos}

Joracy observa que na década de 1930 muitas das obras encenadas na URSS se voltavam para a temática da guerra civil e da defesa da URSS. E neste sentido o espetáculo que mais o impressionou foi $A$ Tragédia Otimista, de Vichnevski, representada no Teatro Kamerny, com direção de Tairov. Infelizmente o autor não comenta muito sobre este espetáculo que tanto o impactou, faz uma longa síntese da obra, deixando exposta toda sua melodramaticidade, mas não dá detalhes da cena e do trabalho atorial. De Tairov assistiu também As noites egipcianas, de Shakespeare-Shaw-Puchkine. Sobre este espetáculo, também apresenta uma longa síntese de seu enredo, sem apontar para os aspectos cênicos, mas comenta:

[...] o espetáculo de Tairov, que ampliou o direito de "destruir"
as peças clássicas, no sentido de "construir" uma obra, como se tivesse
sido possivel reunir Shakespeare, Shaw e Puchkine numa parceria
genial. O que é preciso é servir os interesses da política socialista, pelo
método da assimilação critica. (CAMARGO, 1954, p.127).

Para o autor, o teatro russo da década de 1930, também foi dominado pela tendência de remontar os grandes clássicos da dramaturgia universal. E observa que "a estação teatral de 1933-1934 foi a que maior numero de clássicos incluiu nos repertórios”. (CAMARGO, 1945, p.120). E Meierhold também prestou sua dedicação aos clássicos, fosse para se livrar da censura ou para buscar uma renovação temática, o fato é que ele encenou alguns clássicos neste período, e entre eles A Dama das Camélias, de Alexandre Dumas Filho.

Com uma visão um pouco limitada sobre o trabalho de pesquisa desenvolvido por Meierhold, o autor observa que na fase construtivista e biomecânica deste diretor russo, ele "chegou a abolir o guarda-roupa", e ele se julga privilegiado por ter assistido, no Teatro Meierhold, a encenação de A Dama das Camélias, "já com as roupas que os franceses vestiam na época da peça. Outros protestaram contra a ausência do pano de boca, do velário". (CAMARGO, 1945, p. 80).

Sobre A Dama das Camélias o autor nos aponta alguns procedimentos cênicos de Meierhold. 
[...] o famoso "general" do Exército Teatral [Meierhold,éassim que Joracy o denomina na maioria das vezes] transportou a história de Margarida Gautier do ano de 1850 para o ano de 1870, e utilizou-se dos quadros de Manet e Renoir, como dos desenhos de Roops, para os cenários, e ainda entremeou a ação da peça com as mais velhas canções francesas, o que tornou o drama muito mais emocionante, ao ponto de fazer chorar as mocinhas soviéticas. (CAMARGO, 1945, p.129).

Sobre este espetáculo, Joracy ainda acrescenta mais detalhes cenográficos e a sua percepção da recepção do espetáculo pelo espectador russo, e ainda sobre os aspectos visuais destes espectadores. Sobre a parte estética ele comenta:

O palco estava vazio, os cenários encostados nas paredes, como se tratasse de mero ensaio. Quando soa o terceiro sinal, entraram, tranquilamente, os contra-regras e os maquinistas, colocaram os cenários e os moveis nos respectivos lugares e saíram. Logo entraram os artistas que abrem a representação, tomaram as posições previamente marcadas, e escureceu. Todo o teatro ficou as escuras. Um segundo depois iluminou-se o palco já com os efeitos de luz apropriado, e começou o espetáculo. (CAMARGO, 1945, p. 252)

Nesta fala temos uma das poucas discrições da visualidade do espetáculo, o que é muito significativo, pois na maior parte desta obra, Joracy fala de espetáculos que não assistiu, portanto, narra à voz de outras pessoas. Aqui temos como ele enxergou a obra, e apontando um dos elementos vitais da modernidade cênica: a iluminação. Meierhold, neste espetáculo, provoca uma quebra sensorial no espectador para introduzi-lo no mundo do espetáculo.

Sobre a recepção deste espetáculo, Joracy comenta o seu espanto quando percebeu os soluços e os olhos marejados de lágrimas dos espectadores ante o drama de Margarida. "O fato é que o público chorava francamente". (CAMARGO, 1945, p.252). No intervalo, ele observa, a platéia se diverte no foyer, debate o espetáculo, nem lembrando à dramática platéia que chorava na peça.

Quanto aos espectadores ele comenta que de maneira geral estão vestidos com simplicidade. Mas,

[...] assinalei alguns vestidos elegantes, de seda, algumas jóias, unhas esmaltadas, bonitos penteados, sobretudo grossas tranças em volta da cabeça. [...] Havia gente de todas as classes sociais, ou que antes da Revolução pertencia a classes sociais diferentes, e que ainda se podiam distinguir por um ou outro hábito, pelas atitudes ou maneira de reagir. (CAMARGO, 1945, p.253). 
Talvez, esta percepção sobre o público que freqüentava o teatro revolucionário tenha espantado um pouco alguém que estava à espera de "uma nova sociedade". Mas, o certo é que as transformações foram lentas, e as regalias a uma determinada elite, pertencente ao mundo burocrático russo, já era bastante visível na década de 1930 .

\section{Considerações finais}

Muitos outros aspectos podem ser levantados sobre o ensaio de Joracy Camargo, ela é realmente uma obra bastante preciosa para estudarmos as percepções de um intelectual e dramaturgo brasileiro ante o revolucionário teatro russo, e principalmente, diante do desmonte do que hoje denominamos de Revolucionário Teatro Russo. Como ele vai formulando o seu pensamento sobre o teatro russo pré-revolucionário e as diferentes fases do teatro revolucionário. E, o mais significativo, como ele narra à história que lhe foi repassada e a que ele pode verificar in lócus na URSS. É visível na leitura do ensaio o quanto o autor estava imbuído das diretrizes estabelecidas pelo Partido Comunista Russo e das orientações estabelecidas pelo governo Stalin. Mas, mesmo assim, estamos diante de uma obra rara para estudar o teatro russo a partir da análise de um pensador brasileiro.

\section{Referências bibliográficas}

ABREU, Brício apud CAFEZEIRO, Edwaldo; GADELHA, Carmem. História do Teatro Brasileiro: De Anchieta a Nelson Rodrigues. Rio de Janeiro: UFRJ: FUNARTE, 1996.

CACCIAGliA, Mario. Pequena História do Teatro no Brasil: quatro séculos de teatro no Brasil. São Paulo: EDUSP, 1986.

CAMARGO, Joracy. Teatro Brasileiro // Teatro Infantil. Rio de Janeiro: Ministério da Educação e Saúde, 1937.

CAMARGO, Joracy. O Teatro Soviético. Rio de Janeiro: Leitura, 1945.

PRADO, Décio de Almeida. Teatro: 1930-1980 (ensaio de interpretação). In: BORIS FAUSTO (org.). O Brasil Republicano. Vol III. SP: Difel, 1984. 